\title{
CARDIAC CATHETERIZATION \\ IN CASES OF PATENT INTERAURICULAR SEPTUM, PRIMARY PULMONARY HYPERTENSION, FALLOT'S TETRALOGY, AND PULMONARY STENOSIS
}

BY

\author{
SHEILA HOWARTH, J. MCMICHAEL, AND E. P. SHARPEY-SCHAFER
}

From the Department of Medicine, British Postgraduate Medical School

Received June 12, 1947

The clinical and radiological findings in auricular and ventricular septal defects are well known. In many cases, however, the diagnosis may remain uncertain without pathological examination. The development of the technique of cardiac catheterization as a simple and safe procedure indicated a method for the detection of intracardiac shunts, and a number of reports on the use of the method have already been published (Brannon, Weens, and Warren, 1945; Dexter et al., 1946; and Johnson, Wollin, and Ross, 1947). Not only can interauricular and interventricular shunts be demonstrated, but the amount of blood shunted and the pressure in the chambers of the right heart may be measured. In certain cases the demonstration that no shunt exists may be helpful in diagnosis. This paper reports data in a number of cases that were suspected on clinical grounds of having intracardiac shunts.

\section{METHODS}

The technique of cardiac catheterization and analysis of blood samples were similar to those previously published (McMichael and Sharpey-Schafer, 1944). Arterial samples were obtained from the brachial or femoral arteries. Average normal values are given in Fig. 1. The following procedure may be found convenient.

(1) A preliminary arterial sample indicates whether a right to left shunt has to be considered. We have often found it difficult to judge clinically whether cyanosis resulted from a diminished arterial oxygen saturation or a diminished peripheral flow.

(2) The catheter is passed into the right ventricle. In the absence of conditions causing increased cardiac output the existence of a left to right intracardiac shunt may be suspected if the sampled blood from this position appears bright red like arterial blood, and on analysis is shown to have a high oxygen content.

(3) The catheter is then withdrawn through the tricuspid valves into the right auricle and further samples taken. Brannon, Weens, and Warren (1945) who published data on four cases by similar methods, calculated the magnitude of the left to right shunt through an auricular septal defect from the gas content of auricular blood and the mean gas content of the S.V.C. and I.V.C. samples. With interatrial shunts auricular samples may not be completely mixed, and right ventricular samples are to be preferred if it is desired to make such calculations.

(4) Samples may then be obtained from the superior vena cava and, if possible, from the inferior vena cava.

In cases of right to left shunt the procedure should be carried out as quickly as possible with particular care to avoid clot formation on the tip of the catheter by a continuous drip 
of heparinized saline, since there is a possibility of paradoxical embolism. Preliminary administration of heparin to the patient might be considered to lessen this risk. In children the investigation may be conveniently carried out under a basal anæsthetic.

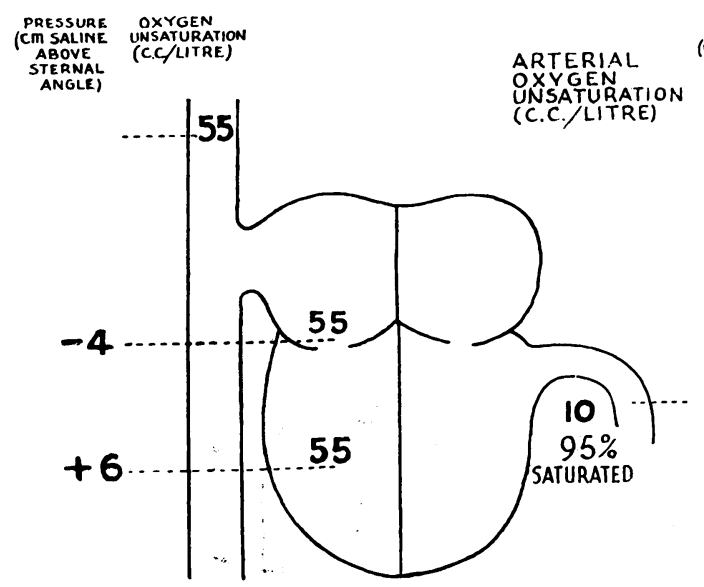

Fig. 1.-Average oxygen unsaturation levels and mean right auricular and ventricular pressure measurements in normal supine subjects.

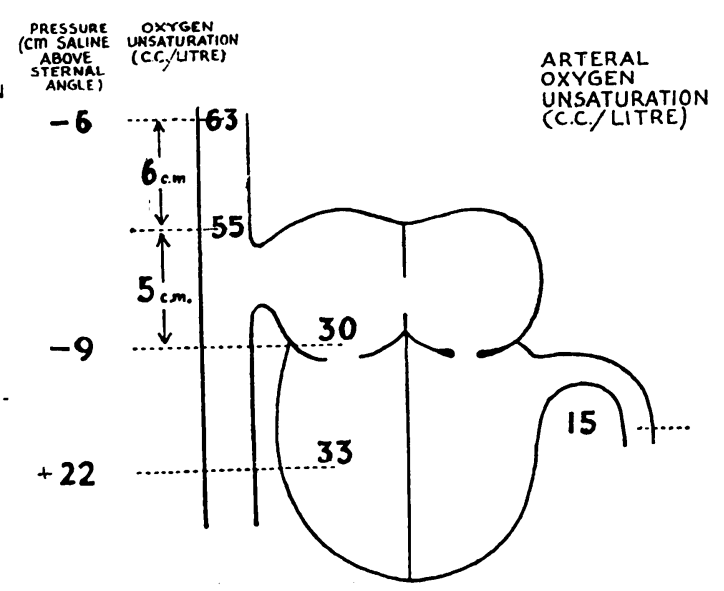

FIG. 2.-Case 1. Data obtained by cardiac catheterization.

\section{CASE Reports}

Case 1. A male, aged 57, was admitted complaining of loss of weight for two years and of bulky fatty stools for six months. An exploratory laparotomy had been performed elsewhere and a carcinoma of the head of the pancreas had been found. Slight dyspnœa on moderate exertion had been present for many years. There was no history of rheumatic fever. On examination there was no dyspnœa, cyanosis, or clubbing. The jugular venous pressure was normal. The blood pressure was $135 / 75$ and the pulse regular at about 80 beats a minute. The heart was moderately enlarged and a systolic thrill and murmur were present, which were maximal at the apex. The hæmoglobin was 78 per cent. A cardiogram was not taken. Chest X-ray (Fig. 4, see p. 295) showed considerable enlargement of the pulmonary arteries, which pulsated strongly. The right ventricle and auricle were enlarged and the left auricle was not enlarged. The aortic knuckle was small. Total pancreatectomy was performed but the patient succumbed to post-operative complications.

Necropsy. The heart weight was $490 \mathrm{~g}$. The pulmonary arteries were greatly enlarged. The right ventricle was thickened and dilated and the left ventricle was normal. The right auricle was enlarged and there was an interatrial septal defect (Fig. 3, see p. 294). The left auricle was normal in size. The mitral valve admitted two fingers and showed slight thickening of the free margins of the cusps.

Comment. The clinical findings suggested patent interauricular septum with possibly mitral incompetence. While catheterization (Fig. 2) clearly demonstrated the presence of a left to right interatrial shunt, the low normal right auricular pressure did not indicate any significant degree of mitral incompetence. Although the systolic thrill and murmur may have resulted from the slight thickening of the free margins of the mitral cusps, demonstrated post-mortem, they may also have been due to relative stenosis in the outflow tract from the right ventricle, in which chamber the mean pressure was considerably increased. During the prolonged and extensive operation for removal of the pancreas in this case, every effort was made to maintain right auricular pressure at or above the normal level by blood transfusion. 


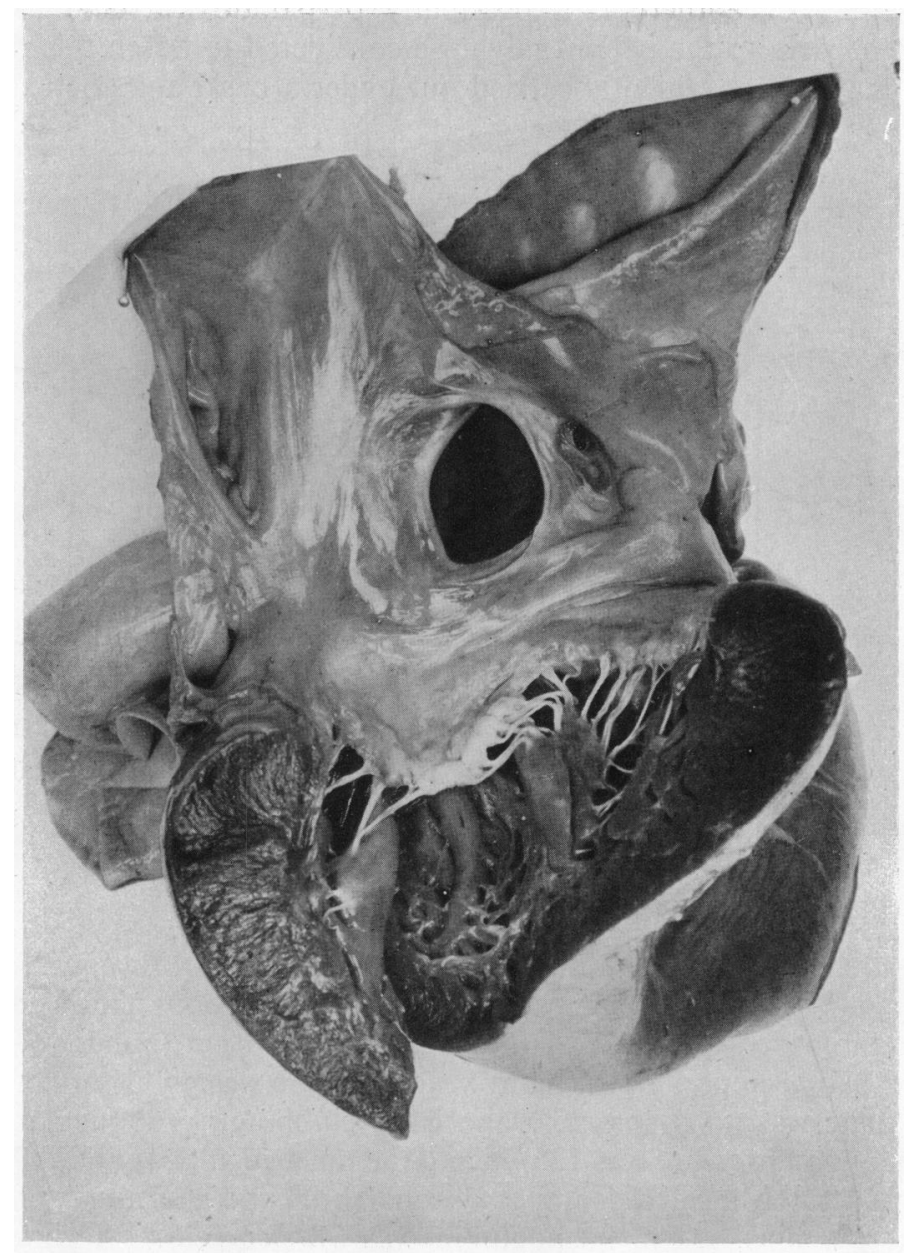

FiG. 3.-Case 1. Heart viewed from the left side to show auricular septal defect and slightly thickened mitral valve.

At one time right auricular pressure was as high as $7 \cdot 5 \mathrm{~cm}$. above the sternal angle; yet analysis of an arterial sample showed that there was no reversal of the shunt which remained from left to right auricle.

Case 2. A man, aged 20, came to hospital for treatment of acne. He had attended a special school until the age of 6 , but there was no history of rheumatism. He played football and did not complain of breathlessness. The jugular venous pressure was not raised and no œdema was present. The blood pressure was 140/85. Auricular fibrillation was present, the apex rate being 120. Systolic and low-pitched diastolic murmurs were heard at the apex. The hæmoglobin was 94 per cent. An electrocardiogram showed auricular fibrillation, rìght axis shift, and slight depression of S-T III. Chest X-ray revealed a small aortic knuckle, enlargement of the pulmonary arteries, and no enlargement of the left auricle (Fig. 5, see p. 295).

Comment. A case of patent interauricular septum. The data (Fig. 6) showed that the shunt was from left to right. The diastolic murmur suggested that mitral stenosis may also have been present. 

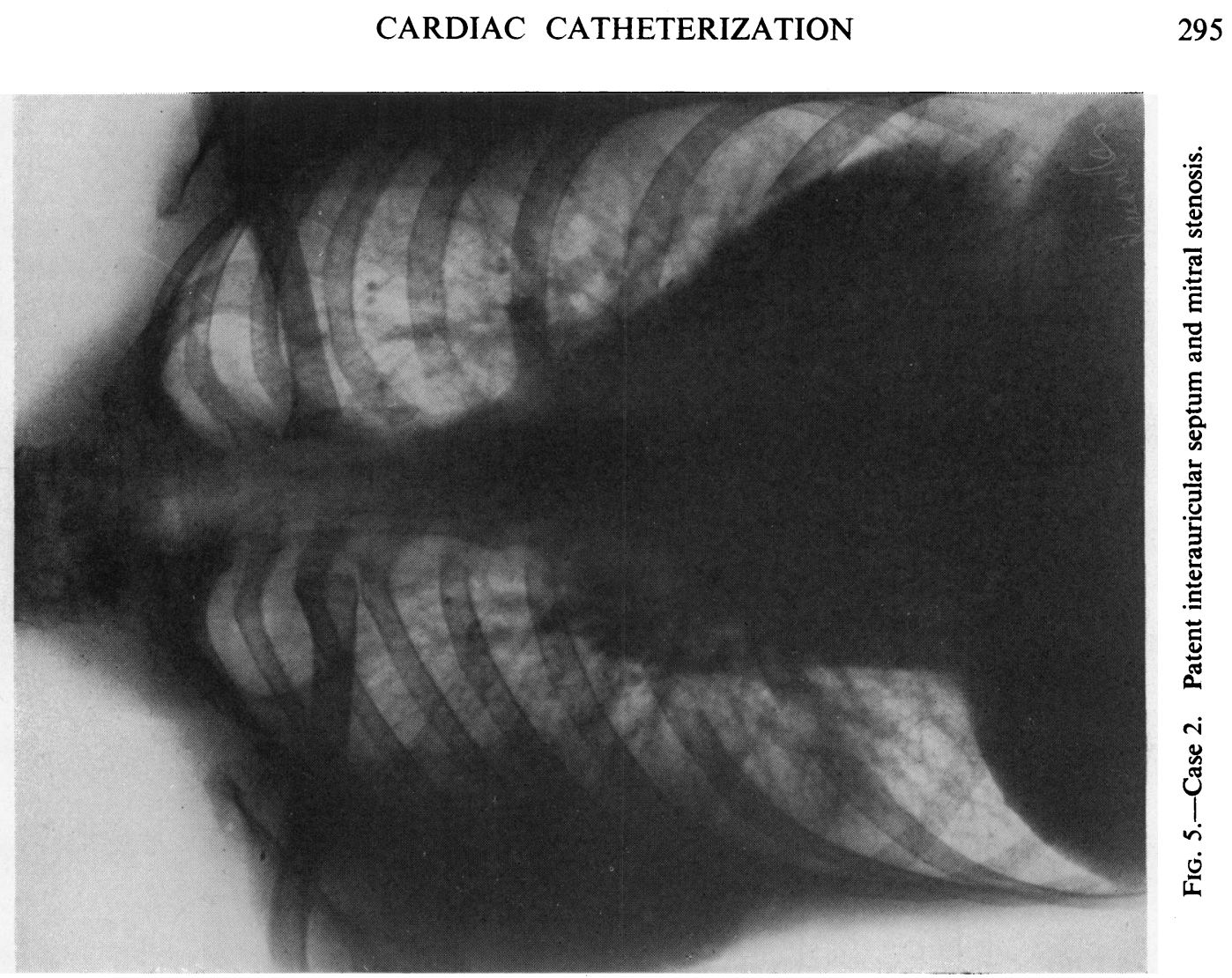

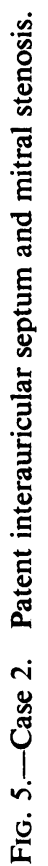

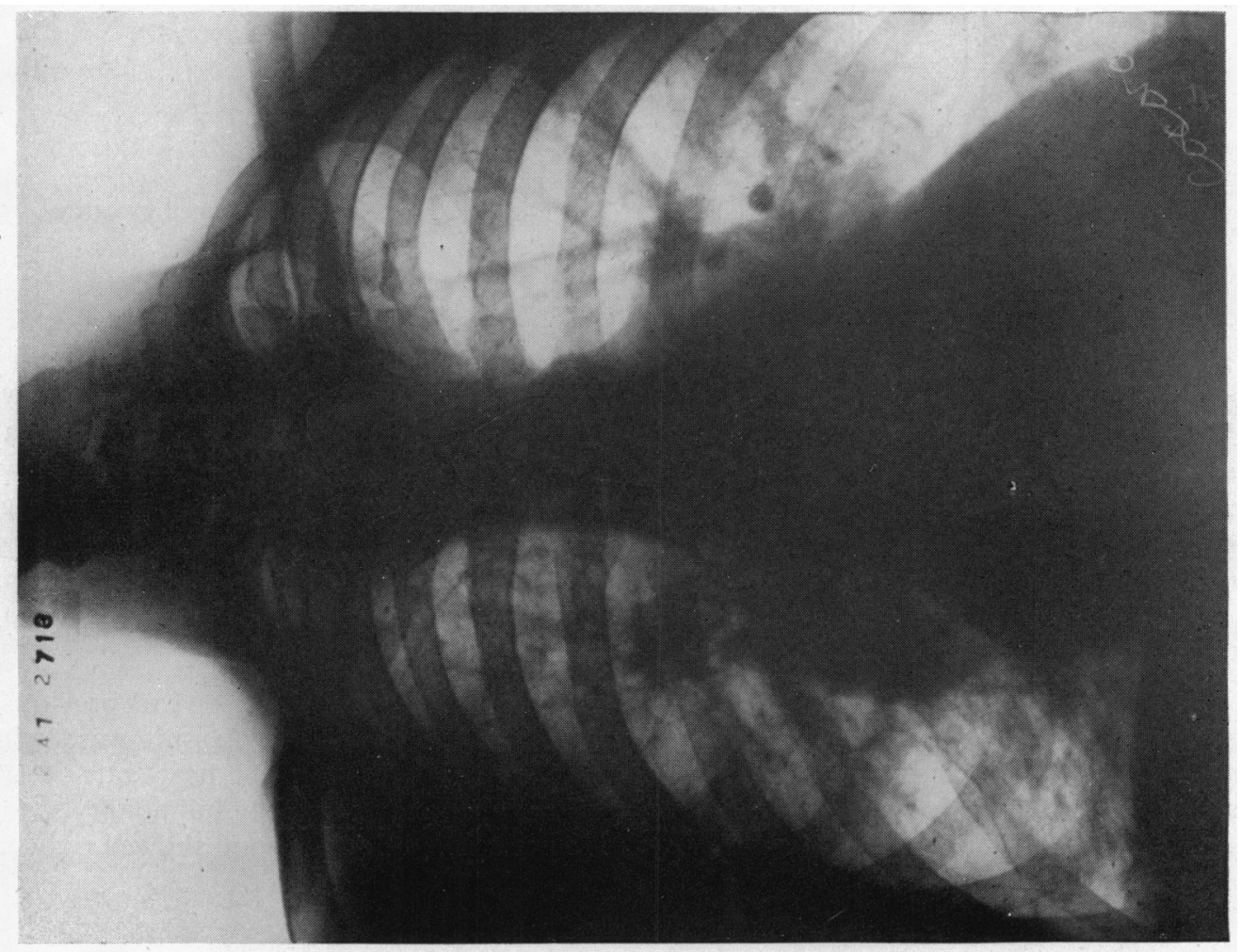

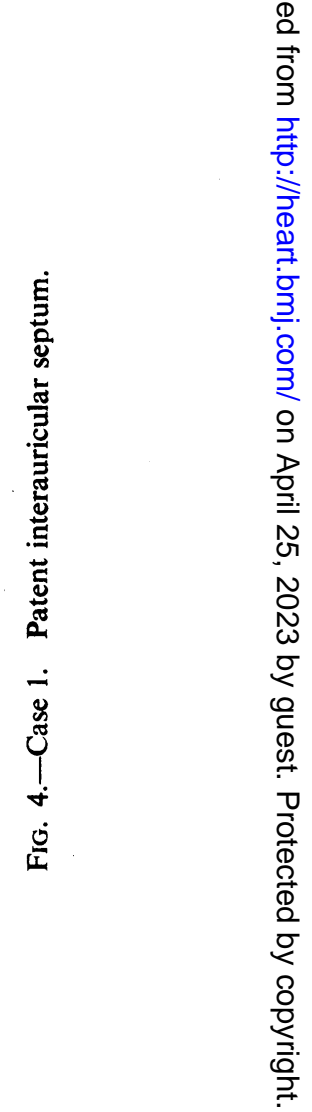


Case 3. A woman, aged 41 , had been diagnosed as suffering from congenital heart disease as a child. She had had no cardiac symptoms until the age of 39 , but during the three months preceding admission to hospital, dyspnœa had been increasing and there had been swelling of the ankles. The jugular venous pressure was raised to $6 \mathrm{~cm}$. above the sternal angle, the liver was enlarged, and œdema was present. The blood pressure was 210/110. The heart rate was 80 , with sinus rhythm. A systolic thrill and loud harsh systolic murmur were present, maximal in the third left interspace and conducted to the apex, and a short diastolic murmur was occasionally heard. The hæmoglobin was 89 per cent. The cardiogram showed no axis shift. There was slight depression of S-T in leads II and III, but all the T waves were upright. X-ray showed enlargement of both right and left ventricles, and moderate enlargement of the left auricle (Fig. 8, see p. 297). The pulmonary arteries were also enlarged.

Post-mortem examination confirmed the diagnosis of patent interauricular septum. The right ventricle was dilated and hypertrophied and there was moderate hypertrophy of the left ventricle. The mitral valve showed some small vegetations. There was cylindrical dilatation of the pulmonary arteries.

Comment. The data showed that the shunt was from left to right (Fig. 7), although right auricular pressure was considerably increased above normal.

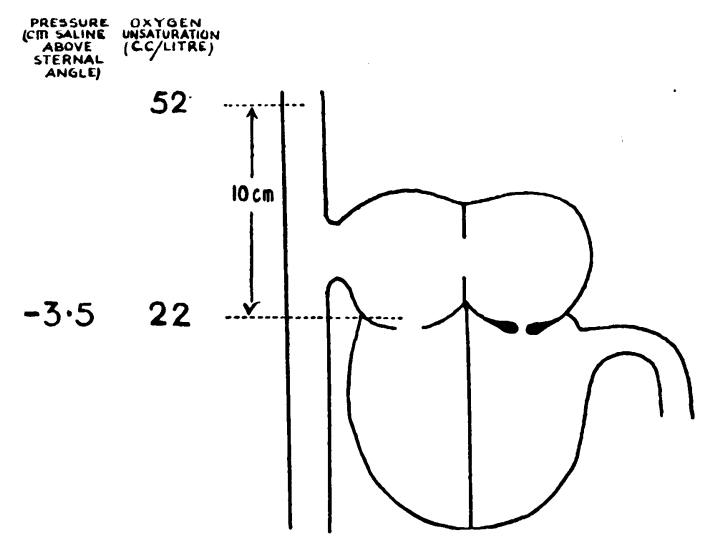

FIG. 6.-Case 2. Data obtained by cardiac catheterization.

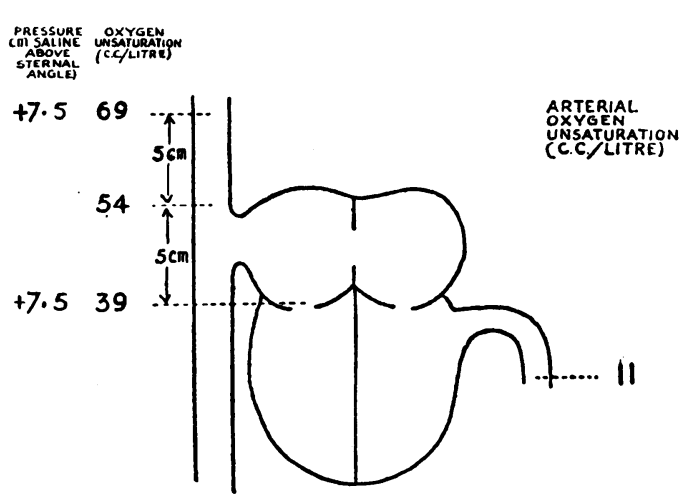

Fig. 7.-Case 3. Data obtained by cardiac catheterization.

Case 4. A woman, aged 40, gave a history of effort dyspnœa for 3-4 years and of attacks of nocturnal dyspnœa for 2 years. She had had rheumatic fever at the age of 11 years. The jugular venous pressure was not raised and there was no œdema. The blood pressure was $125 / 90$. The heart rate was 108 , with sinus rhythm. A harsh systolic murmur was heard over the lower part of the left side of the sternum, and the pulmonary second sound was increased. The hæmoglobin was 108 per cent. A cardiogram showed sinus rhythm, right axis shift and S-T II and S-T III depression. Chest X-ray showed enlargement of the right ventricle and of the pulmonary arteries (Fig. 9, see p. 297). The left auricle was not enlarged.

Comment. A case of patent interauricular septum. The data (Fig. 10) showed that the shunt was from the left to the right.

Case 5. A man, aged 31, had had two attacks of rheumatic fever 11 and 8 years previously. He complained of slight effort dyspnœa for 1 year. The jugular venous pressure was slightly raised. No œdema was present. The blood pressure was 105/70; the heart rate 70 , and the rhythm regular. A systolic murmur was present at the apex and the pulmonary second sound was accentuated. The hæmoglobin was 118 per cent. A cardiogram showed right axis 

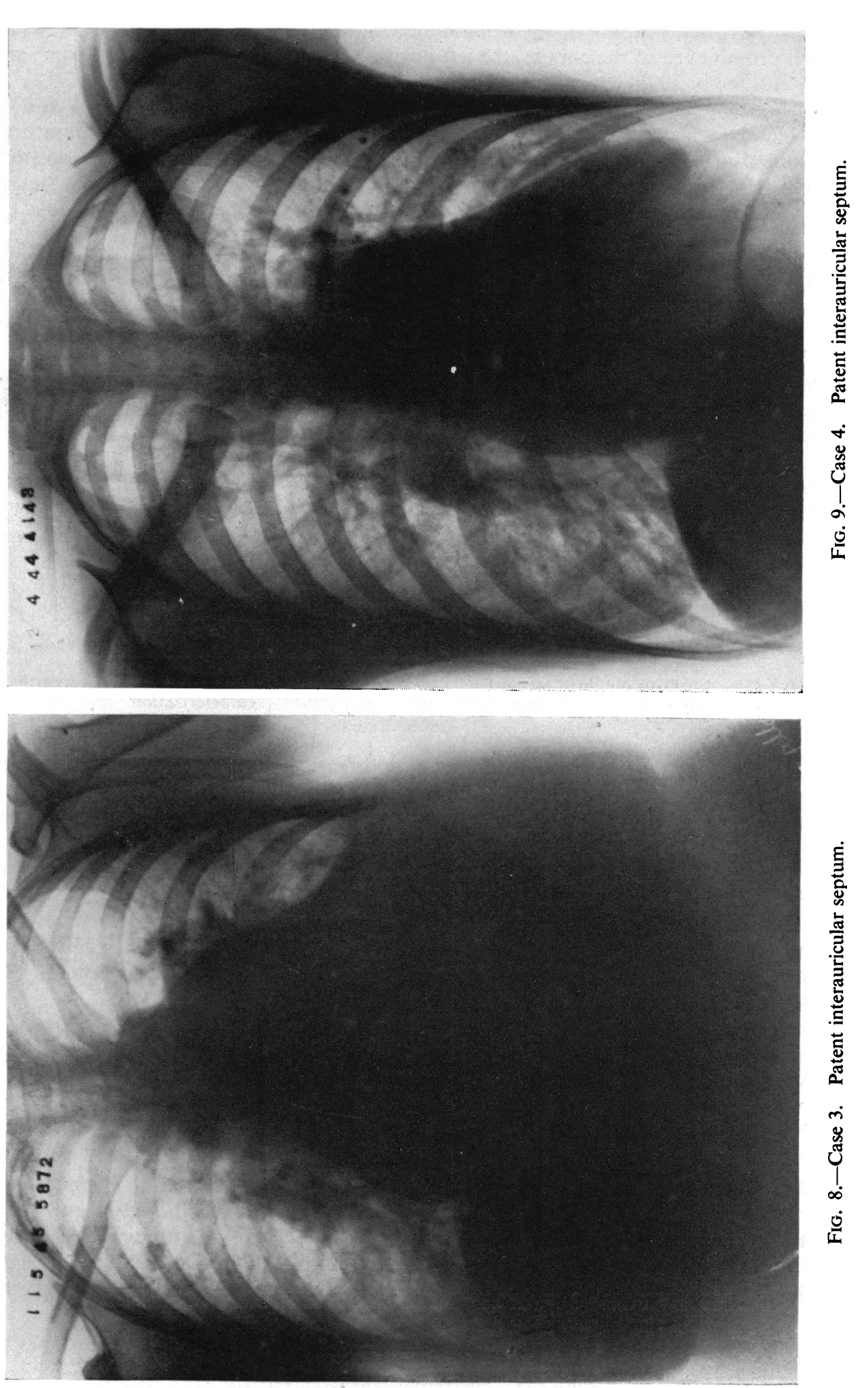
shift with S-T III depression. X-ray examination showed enlargement of right and left ventricles with prominence of the conus: the left auricle was not enlarged and the aortic shadow small (Fig. 12, see p. 299).

Comment. The difference in oxygen content between superior vena caval and right auricular blood indicated a left to right auricular shunt (Fig. 11). The lower unsaturation figure obtained in the ventricle may have been due to inadequate mixing in the position of sampling in the auricle. The possibility of a small right to left ventricular shunt is suggested by the lowered arterial oxygen saturation.

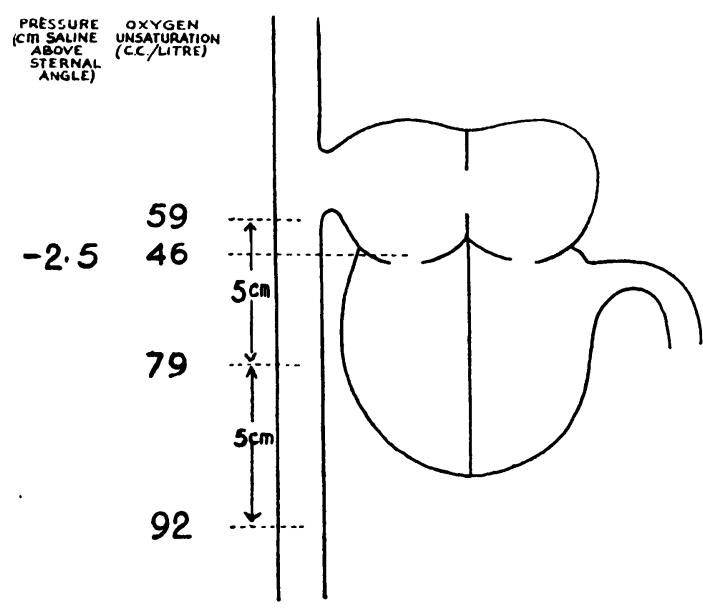

FIG. 10.-Case 4. Data obtained by cardiac catheterization.

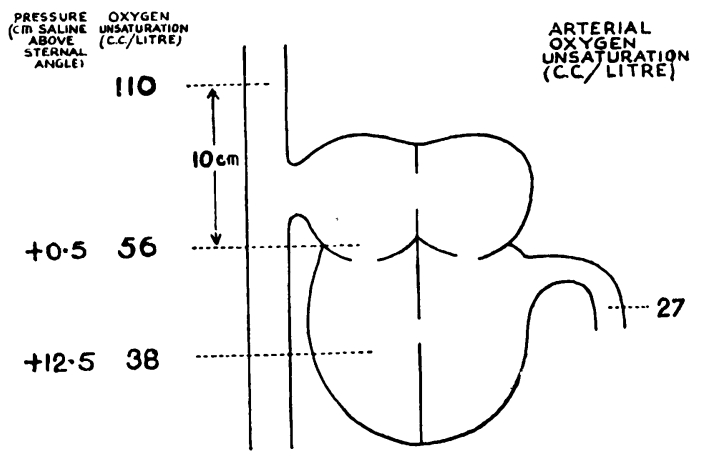

FIG. 11.-Case 5. Data obtained by cardiac catheterization.

Case 6. A woman, aged 26, had suffered from breathlessness and blueness of the lips on exertion for one year. There was no history of rheumatic fever. The jugular venous pressure was raised to $1 \mathrm{~cm}$. above sternal angle level, but the liver was not enlarged and there was no œdema. The blood pressure was 114/76. There was a harsh systolic murmur at the apex and the pulmonary second sound was accentuated. A cardiogram showed sinus rhythm, right axis shift, and depression of S-T in leads II and III. P II was $0.3 \mathrm{mv}$. A chest X-ray showed enlargement of the right ventricle, the conus and the pulmonary arteries, but no enlargement of the left auricle (Fig. 13, see p. 299). The vital capacity was $2300 \mathrm{ml}$. She developed severe cardiac failure and cachexia with extreme peripheral cyanosis. Death occurred 18 months after the first admission to hospital.

Post-mortem examination. The heart weighed $481 \mathrm{~g}$. and showed hypertrophy and dilatation of the right ventricle. The right auricle was dilated, but no septal defect was found. The left ventricle and auricle were normal, and so were the valves. Atheroma of the pulmonary arteries with some recent thrombosis was found, and the small branches of the pulmonary artery showed great thickening of the arterial wall and reduction of the size of the lumen. There was no pulmonary emphysema.

Comment. The samples from the right ventricle and auricle showed no evidence of a left to right shunt (Fig. 14). Arterial saturation was originally normal though slightly reduced 8 months later when severe failure was present (Fig. 15). There was no evidence of right to left shunt or of chronic disease in the lungs. These findings with the demonstration of a greatly raised mean right ventricular pressure suggested a diagnosis of primary pulmonary hypertension. The post-mortem findings supported this view. 


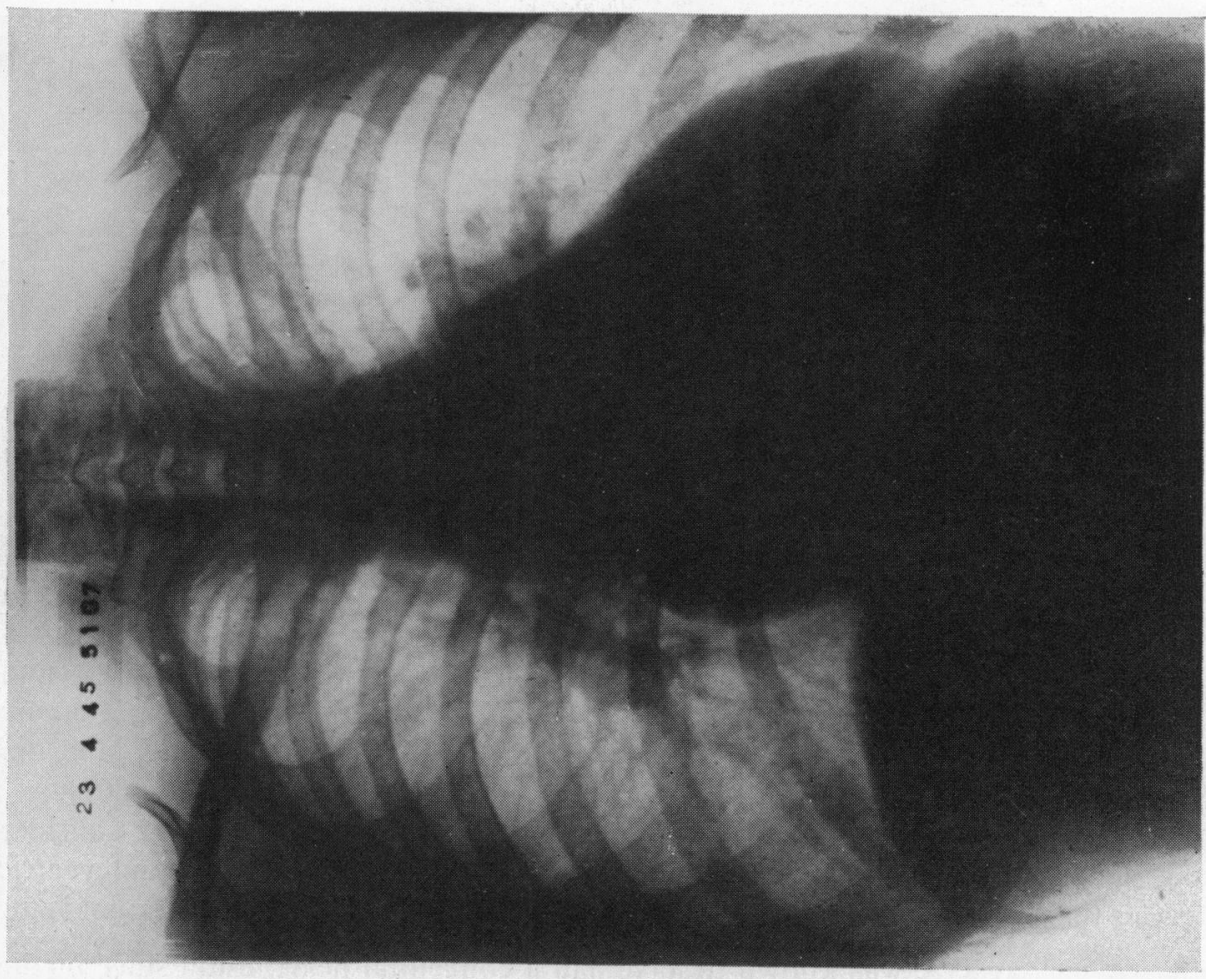

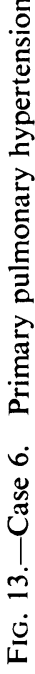

.
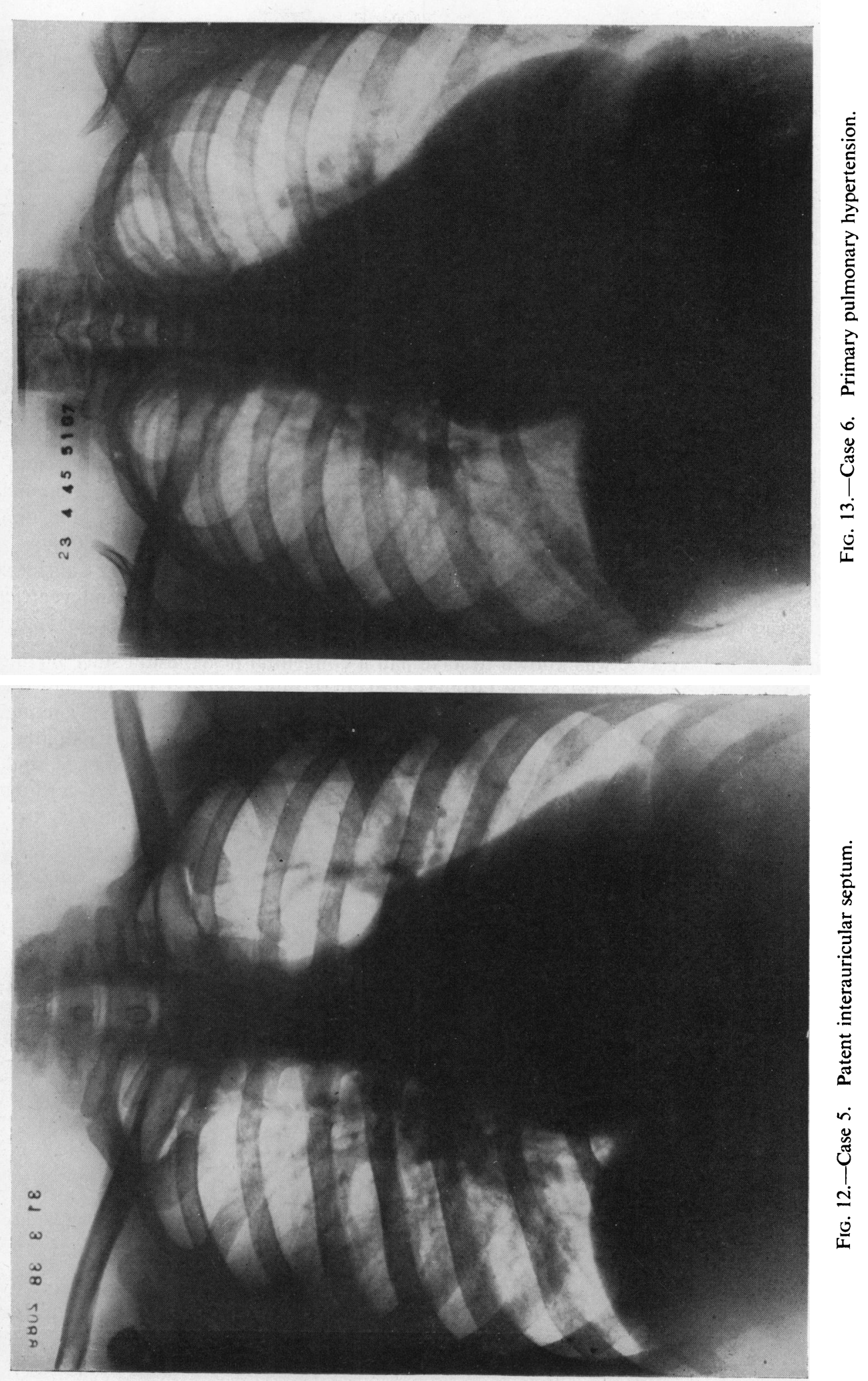

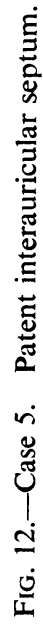

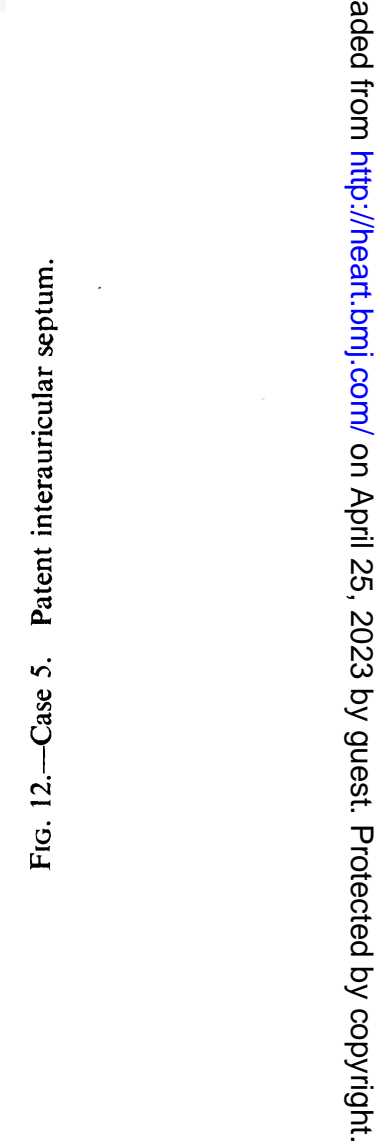




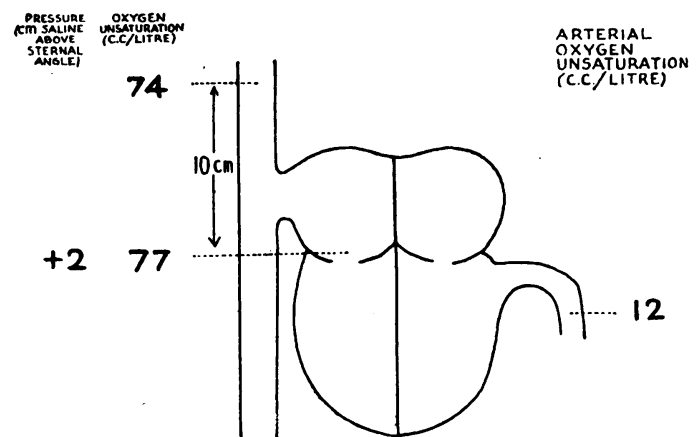

FIG. 14.-Case 6. Initial data obtained by cardiac catheterization.

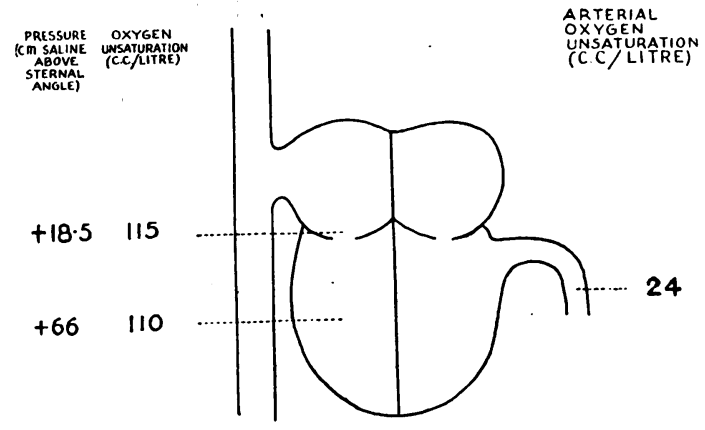

FIG. 15.-Case 6. Data obtained 8 months later when severe failure was present.

Case 7. A boy, aged 15, had been diagnosed at the age of 4 as a case of Fallot's tetralogy. He was admitted to hospital following hæmoptysis. He was cyanosed, showed defective growth, and had clubbing of the fingers. The jugular venous pressure was not increased, the liver was not enlarged and there was no œdema. The blood pressure was $80 / 20$, and the heart rate 96 , the rhythm being regular. A harsh systolic murmur was heard, maximal in the third left interspace. A cardiogram showed sinus rhythm, right axis shift and depression of S-T III. Chest X-ray showed a classical "sabot" heart (Fig. 18, see p. 301).

Comment. The decrease in the saturation of arterial blood indicated a considerable shunt from right to left (Fig. 16). The difference between right auricular and ventricular blood suggests the possibility that there was also some mixing from the left to the right ventricle.

Case 8. A girl, aged 8, was known to have had a congenital heart lesion since birth. In recent months she had become easily fatigued and after mild exertion the jugular venous pressure became elevated. On examination there was no clubbing or cyanosis. The jugular venous pressure was at the level of the sternal angle at rest and the liver was palpable. A systolic thrill and a harsh systolic murmur were present in the third left interspace, and the pulmonary second sound was accentuated. The blood pressure was 100/50. A cardiogram showed right preponderance. Chest X-ray showed enlargement of the pulmonary arteries and right ventricle (Fig. 19, see p. 301).

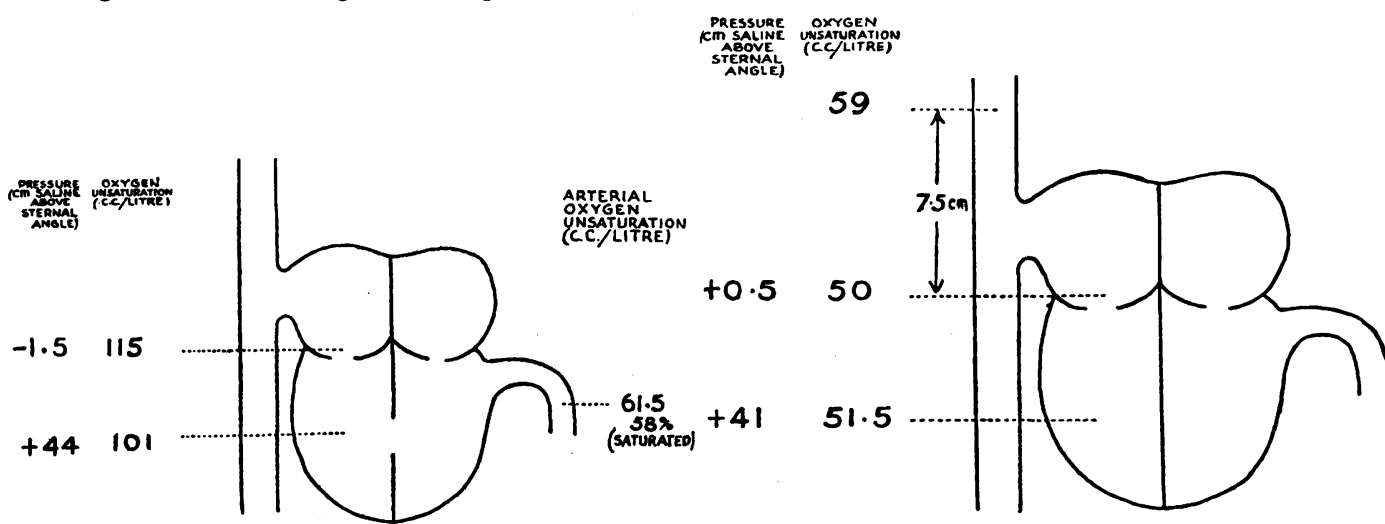

Fig. 16.-Case 7. Data obtained by cardiac catheterization.

FIG. 17.- Case 8. Data obtained by cardiac catheterization.

Comment. In view of a pulse pressure of $50 \mathrm{~mm}$. Hg. patent ductus was considered, while a left to right auricular shunt could not be excluded on clinical grounds. Catheterization

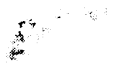




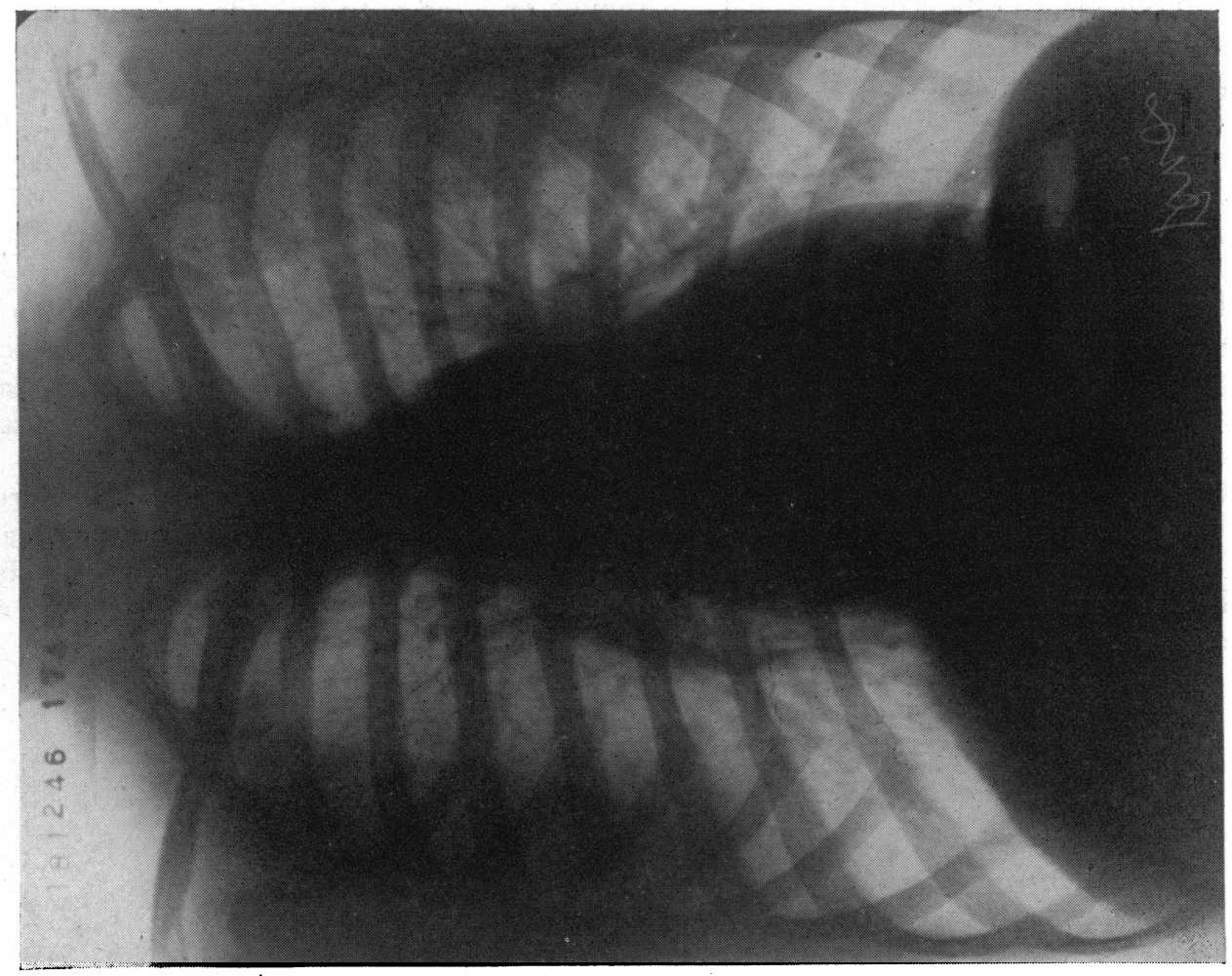

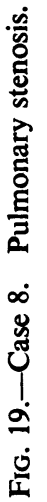

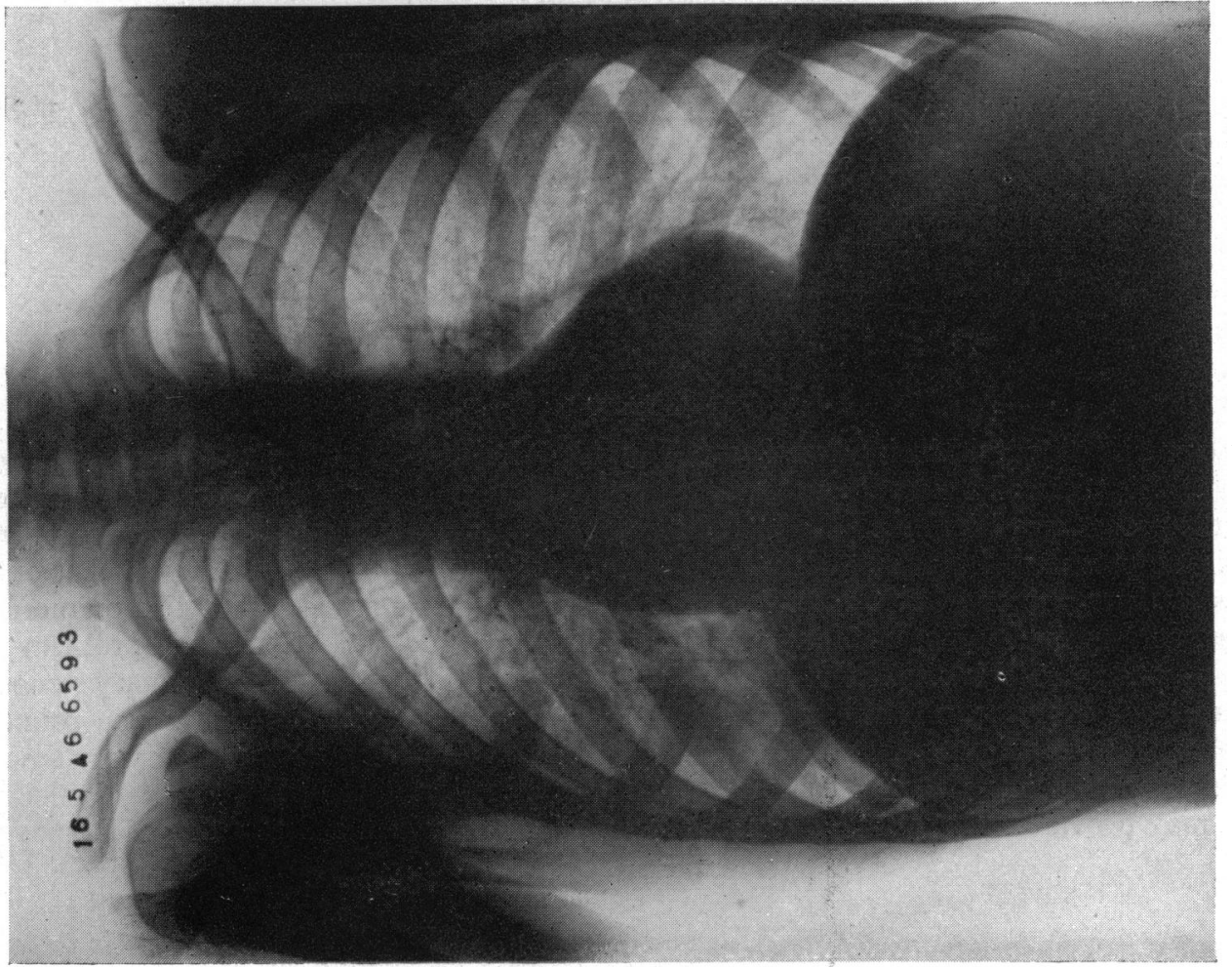

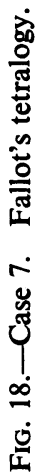


revealed no evidence of a shunt (Fig. 17). Although an attempt to pass the catheter into the pulmonary artery failed, the greatly increased right ventricular pressure made a diagnosis of pulmonary stenosis almost certain.

Case 9. A boy, aged 13, was known to have had cardiac murmurs since birth. He played games at school and there was no history of cyanosis or excessive breathlessness. The jugular venous pressure was not raised and there was no œdema. The blood pressure was $90 / 40$ and the heart rate was regular at 90. A thrill, a harsh systolic murmur, and a soft diastolic murmur were present in the pulmonary area, maximal in the second left interspace. The pulmonary second sound was accentuated. A diastolic murmur was present at the apex. The hæmoglobin was 91 per cent. A cardiogram was normal. X-ray examination showed considerable enlargement of the right ventricle and the pulmonary arteries. The left ventricle was also slightly enlarged. There was no left auricular enlargement.

Comment. A case of patent ductus arteriosus (Fig. 20). The mean pulmonary arterial pressure was surprisingly high, in view of the systemic blood pressure. Considerable increase in right ventricular work from this high pressure may have resulted in hypertrophy comparable with the left ventricular hypertrophy from increased output, since the cardiogram shows no axis deviation.

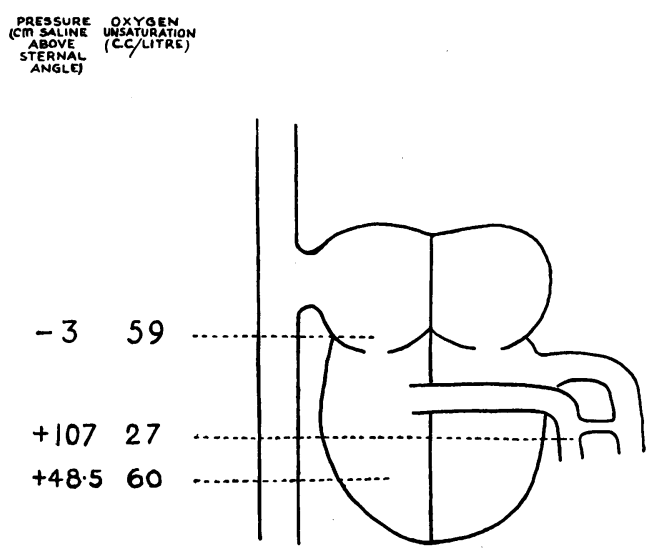

FIG. 20.

\section{Discussion}

The precise diagnosis during life of congenital heart lesions has now more than an academic interest. Ligation of a patent ductus arteriosus is a well-established method of treatment, while the procedures of Blalock and Taussig (1945) in Fallot's tetralogy seem very promising. Even if the presence of a patent ductus is obvious, it may be of value to know whether other lesions are present or absent when considering ligation. Enlargement of the pulmonary arteries, as a main finding, has long presented a difficult differential diagnostic problem for clinicians and radiologists. Patent interauricular septum, mitral stenosis, pulmonary stenosis, Eisenmenger's complex, patent ductus arteriosus, cor pulmonale from emphysema, primary pulmonary hypertension and rupture of a syphilitic aorta into the pulmonary artery are among the conditions that may have to be considered. Investigation of the right heart by catheterization may provide the answer, or at least further data on which a firmer diagnosis may be based. 
The conditions under which a left to right auricular shunt is reversed remain obscure. Like Brannon, Weens, and Warren, we have tried various procedures such as the Valsalva experiment and different postures without producing any change in the arterial oxygen saturation. The intrathoracic pressure rises steeply during a Valsalva, and all chambers of the heart may be affected equally. When the mitral valve is stenosed, any procedure tending to raise the pressure in the right auricle may result in at least an equal rise in the left so that the shunt remains left to right. Case 3 shows that mean pressure in the right auricle may be high and the shunt still left to right. In Case 1, where the mitral valve was probably functionally normal, a high right auricular pressure produced by transfusion did not reverse the shunt.

It is difficult to make an exact quantitative estimate of the proportion of blood shunted from the left to the right heart. Brannon, Weens, and Warren estimated that in some cases of patent interauricular septum the output of the right ventricle might be as much as three times that of the left. While the systemic blood flow may be estimated from vena caval samples, it is not so easy to get an exact estimate of the output of the right heart. The inflowing stream of arterial blood from the left auricle makes it difficult to be certain that samples from the right heart are completely " mixed." This difficulty is illustrated in Case 5.

The normal mean right ventricular pressure is from 10 to $15 \mathrm{~cm}$. of saline above the mean auricular pressure. The high ventricular pressures recorded in Cases 6, 7, and 8 indicated increased resistance in either the outflow tract of the right ventricle or in the pulmonary arteries. In congestive heart failure from any cause, mean right ventricular pressure may be increased. This finding, therefore, is more significant of organic obstruction in the right outflow tract if right auricular pressure is normal.

\section{SUMMARY}

Samples of blood from the right auricle and right ventricle may be obtained by cardiac catheterization in cases of suspected cardiac shunts. Blood so obtained contains more oxygen than vena caval blood if the shunt is from left to right. Right to left shunts may be detected by a reduced arterial oxygen saturation in the presence of normally functioning lungs.

Two of the five cases with patent interauricular septum showed a conspicuous increase in right auricular pressure with the shunt still left to right.

A case with enlarged pulmonary arteries and a normal arterial oxygen saturation showed no evidence of a shunt and a greatly increased mean right ventricular pressure. A diagnosis of pulmonary hypertension was confirmed post-mortem.

A case of Fallot's tetralogy showed an increased mean right ventricular pressure. The data suggested some left to right mixture of blood although the main shunt was from right to left.

A child with enlarged pulmonary arteries showed no evidence of a shunt. Mean right ventricular pressure was greatly increased and a diagnosis of pulmonary stenosis was made.

A case of patent ductus arteriosus showed a greatly raised mean pulmonary arterial pressure, a considerably raised right ventricular pressure, and highly oxygenated pulmonary arterial blood samples.

- We are indebted to the Medical Research Council for a personal grant to one of us (S. H.) and for an expenses grant.

\section{REFERENCES}

Blalock, A., and Taussig, H. B. (1945). J. Amer. med. Ass., 128, 188.

Brannon, E. S., Weens, H. S., and Warren, J. V. (1945). Amer. J. med. Sci., 210, 480.

Dexter, L., Burwell, C. S., Haynes, F. W., and Seibel, R. E. (1946). Bull. New Eng. Med. Center, 8, 113.

Johnson, A. L., Wollin, D. G., and Ross, J. B. (1947). Canad. med. Ass. J., 56, 249.

McMichael, J., and Sharpey-Schafer, E. P. (1944). Brit. Heart J., 6, 33. 